\title{
Epidemiology of Fractures in England and Wales
}

\author{
T. P. van STAA,,${ }^{1,2,3}$ E. M. DENNISON, ${ }^{1}$ H. G. M. LEUFKENS, ${ }^{2}$ and C. COOPER ${ }^{1}$ \\ ${ }^{1}$ MRC Environmental Epidemiology Unit, University of Southampton, Southampton General Hospital, Southampton, UK \\ ${ }^{2}$ Department of Pharmacoepidemiology and Pharmacotherapy, University of Utrecht, Utrecht, The Netherlands \\ ${ }^{3}$ Procter \& Gamble Pharmaceuticals, Staines, UK
}

\begin{abstract}
Records from the General Practice Research Database were used to derive age- and gender-specific fracture incidence rates for England and Wales during the period 1988-1998. In total, 103,052 men and 119,317 women in the sample of 5 million adults sustained a fracture over $\mathbf{1 0 . 4}$ million and $\mathbf{1 1 . 2}$ million person-years (py) of follow-up. Among women, the most frequent fracture sites were the radius/ulna (30.2 cases per 10,000 py) and femur/hip (17.0 per 10,000 py). In men, the most common fracture was that of the carpal bones $\mathbf{( 2 6 . 2}$ per $10,000 \mathrm{py}$ ); the incidence of femur/hip fracture was 5.3 per 10,000 py. Varying patterns of fracture incidence were observed with increasing age; whereas some fractures became more common in later life (vertebral, distal forearm, hip, proximal humerus, rib, clavicle, pelvis), others were more frequent in childhood and young adulthood (tibia, fibula, carpus, foot, ankle). The lifetime risk of any fracture was $53.2 \%$ at age 50 years among women, and $20.7 \%$ at the same age among men. Whereas fractures of the proximal femur and vertebral body were associated with excess mortality over a 5 year period following fracture diagnosis among both men and women, fractures of the distal forearm were associated with only slight excess mortality in men. This study provides robust estimates of fracture incidence that will assist health-care planning and delivery. (Bone 29: 517-522; 2001) @ 2001 by Elsevier Science Inc. All rights reserved.
\end{abstract}

Key Words: Osteoporosis; Epidemiology; Fracture; Incidence; Mortality; Risk.

\section{Introduction}

Osteoporotic fractures represent an enormous public health burden. Worldwide, there were an estimated 1.66 million hip fractures in 1990, about 1,197,000 in women and 463,000 in men. ${ }^{8}$ Epidemiological studies from North America have estimated the lifetime risk of common fragility fractures to be $17.5 \%$ for hip fracture, $15.6 \%$ for clinically diagnosed vertebral fracture, and $16 \%$ for distal forearm fracture among white women aged 50 years. ${ }^{16}$ Corresponding risks among men are $6 \%, 5 \%$, and $2.5 \%$. Fracture incidence data relating to the British population are, however, more scarce. In Cardiff, Wales, a recent study reported an all-fracture incidence rate of 235/10,000 per year among men and of 188/10,000 per year among women. ${ }^{14}$ An earlier study

Address for correspondence and reprints: Professor C. Cooper, MRC Environmental Epidemiology Unit, Southampton General Hospital, Southampton SO16 6YD, UK. E-mail: cc@mrc.soton.ac.uk based in Leicester ${ }^{11}$ suggested substantially lower rates: annual incidence of fractures at all sites of around 100/10,000 per year in men and 81/10,000 per year among women. Robust estimates of fracture incidence are required to plan healthcare delivery, as well as to characterize geographic and temporal variation. In this study, we utilize records from the General Practice Research Database to report age- and gender-specific fracture incidence rates for the adult population of England and Wales as a whole, during the period 1988 to 1998 .

\section{Subjects and Methods}

General practitioners (GP) play a key role in the health-care system of the UK, as they are responsible for primary health-care and specialist referrals. The information in this study was obtained from the General Practice Research Database (GPRD), which contains the computerized medical records of 683 general practices in the UK. The population in GPRD is broadly representative of the UK population in age and gender structure, with a national coverage of about $6 \% .{ }^{24}$ The data accrued include demographic information about the patient, prescription details, clinical events, preventive care provided, referrals to specialist care, hospital admissions, and their major outcomes. Clinical data are stored and retrieved by means of Oxford Medical Information Systems (OXMIS) and READ codes for diseases or causes of morbidity and mortality that are cross referenced to the International Classification of Diseases, ninth edition (ICD-9). The data quality of each entry into GPRD is measured against specific targets, developed by comparisons with external statistics, to ensure research standards are met. Only data from practices that pass this quality control are compiled to form the GPRD. Several independent validation studies have shown that the database has a high level of completeness and validity. ${ }^{24}$ The GPRD is owned by the Department of Health and managed by the Medicines Control Agency in the UK.

\section{Study Population}

The study population consisted of all permanently registered patients aged $\geq 20$ years who had a fracture recorded in their medical record during the period of time from the enrollment date of their practice in GPRD until the end of data collection. The duration of data collection was from 1988 until 1998. The fracture types were classified according to the ICD-9 categories. These included skull (ICD-9 categories 800-804), vertebra (805 or 806), rib (807), pelvis (808), clavicle (810), scapula (811), humerus (812), radius/ulna (813), carpus (814 to 817), femur/hip $(820 / 821)$, patella (822), tibia/fibula/ankle (823 or 824$)$, foot (825 or 826$)$, or unspecified fractures $(809,818,819,827-829)$. 
Table 1. Distribution of fractures and incidence rates standardized to the UK population

\begin{tabular}{|c|c|c|c|c|c|c|}
\hline \multirow[b]{2}{*}{ Fracture site } & \multicolumn{2}{|c|}{ Men } & \multicolumn{2}{|c|}{ Women } & \multicolumn{2}{|c|}{ Both } \\
\hline & No. of cases & Rate per 10,000 py & No. of cases & Rate per 10,000 py & No. of cases & Rate per 10,000 py \\
\hline All & 103,052 & 99.5 & 119,317 & 107.1 & 222,369 & 103.4 \\
\hline Radius/ulna & 13,581 & 13.1 & 33,366 & 30.2 & 46,947 & 22.0 \\
\hline Carpus & 26,649 & 26.2 & 11,563 & 10.4 & 38,212 & 18.0 \\
\hline Tibia/fibula/ankle & 15,474 & 15.0 & 16,164 & 14.6 & 31,638 & 14.8 \\
\hline Foot & 12,584 & 12.2 & 13,358 & 11.9 & 25,942 & 12.1 \\
\hline Femur/hip & 5755 & 5.3 & 19,179 & 17.0 & 24,934 & 11.4 \\
\hline Ribs & 10,256 & 9.7 & 7128 & 6.4 & 17,384 & 8.0 \\
\hline Humerus & 5558 & 5.3 & 11,458 & 10.3 & 17,016 & 7.9 \\
\hline Skull & 9791 & 9.7 & 4054 & 3.6 & 13,845 & 6.6 \\
\hline Vertebra & 3406 & 3.2 & 6195 & 5.6 & 9601 & 4.5 \\
\hline Clavicle & 4162 & 4.1 & 2266 & 2.0 & 6428 & 3.0 \\
\hline Pelvis & 1086 & 1.0 & 3527 & 3.1 & 4613 & 2.1 \\
\hline Patella & 1114 & 1.1 & 1548 & 1.4 & 2662 & 1.2 \\
\hline Scapula & 958 & 0.9 & 677 & 0.6 & 1635 & 0.8 \\
\hline
\end{tabular}

KEY: py, person-years.

A high level of validity for the recording of fractures in GPRD has been reported. ${ }^{23}$

Age- and gender-specific fracture incidence rates in the GPRD population were calculated by dividing the number of patients with a fracture by the total person-years of follow-up (detailed incidence estimates are available from the corresponding author). The total person-time was the sum of the number of patients registered on the database at July 1 of each calendar year. In the case of a patient suffering several fractures during follow-up, only the first fracture was used in the calculation of incidence rates. A directly standardized fracture rate was estimated using the age and gender structure of the population of England and Wales in 1992. Lifetime risks of fracture were then estimated using the age- and gender-specific incidence rates. For a hypothetical cohort of 100,000 patients, the number of years of life lived at each year of age was estimated using all-cause mortality rates for the general population of England and Wales. ${ }^{19}$ The estimated years of life were multiplied by the corresponding fracture incidence rates to give the expected number of fractures in the hypothetical cohort for each year of age. ${ }^{2,21}$
The observed survival following a fracture was calculated using lifetable methods. Follow-up was based on the time from fracture until death or the end of the study. Expected survival was estimated using the age- and gender-specific person-years of follow-up in the study population and all-cause mortality rates for the general population of England and Wales. ${ }^{19}$ For each period of time following the fracture, the total number of expected deaths was calculated by multiplying the age- and genderspecific durations of follow-up and mortality rates. The probability of mortality was the number of expected deaths divided by the number of patients at risk at the midpoint of each time period. The cumulative survival probability was based on the product of the corresponding conditional survival probabilities.

\section{Results}

A total of 103,052 men sustained one or more fractures over $10,427,627$ person-years of follow-up, in contrast to 119,317 women over 11,191,844 person-years of follow-up. Table 1 shows the distribution of fractures and the standardized incidence

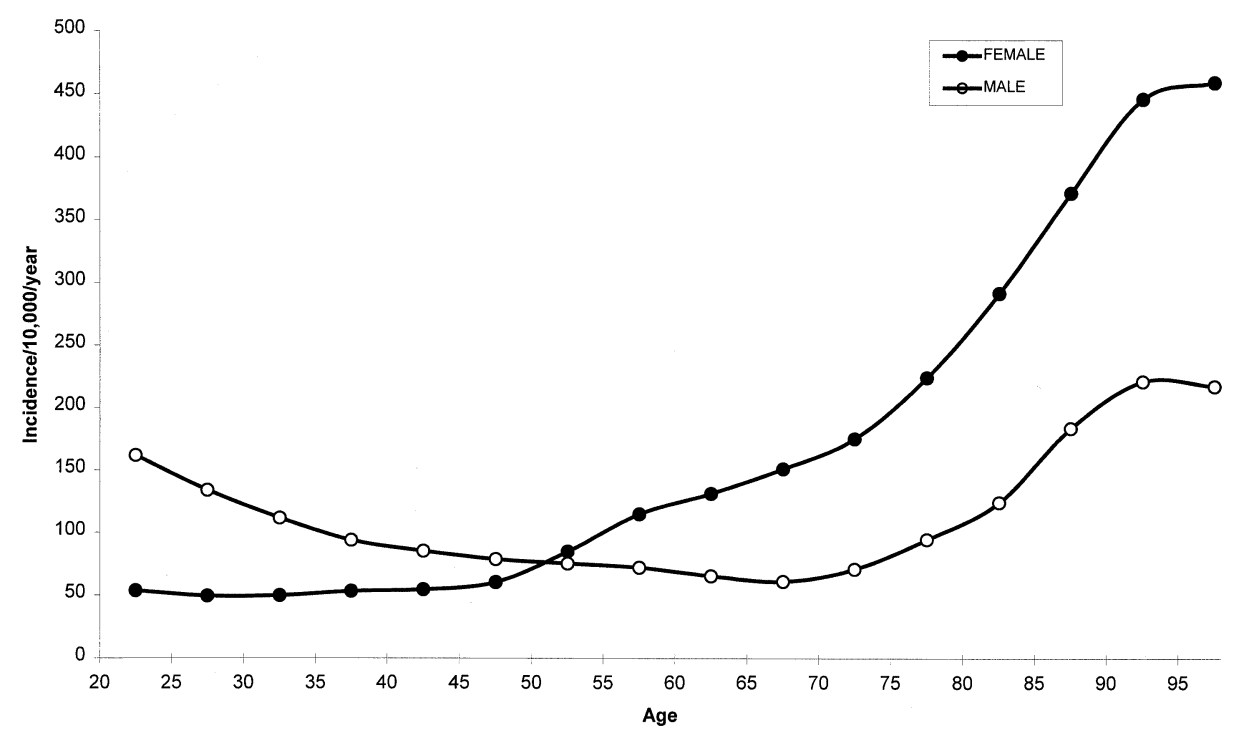

Figure 1. Age- and gender-specific incidence of fractures at any site among 5 million adults registered in the General Practice Research Database, 1988 to 1998 . 
(a)
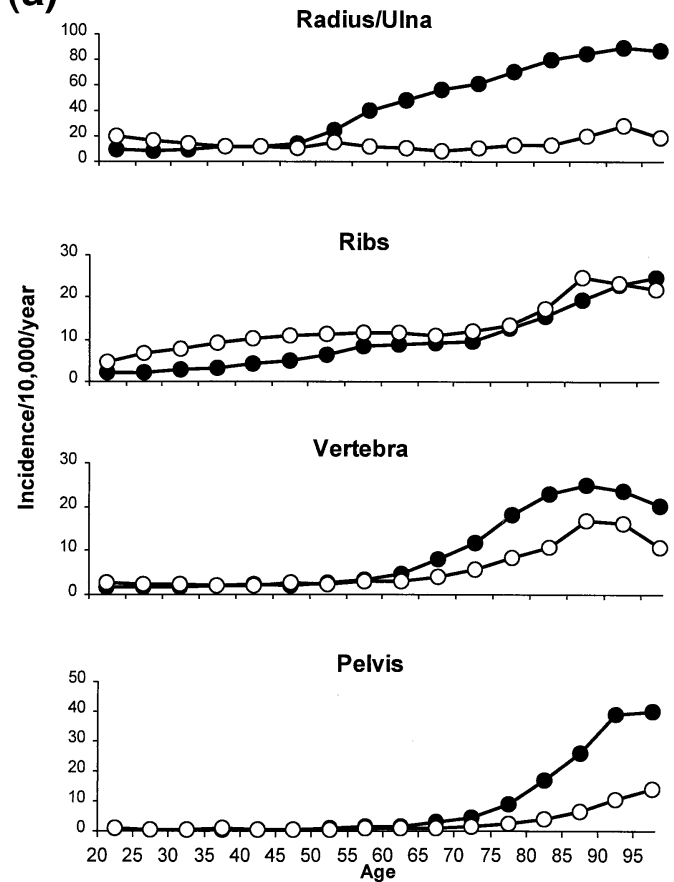

(b)
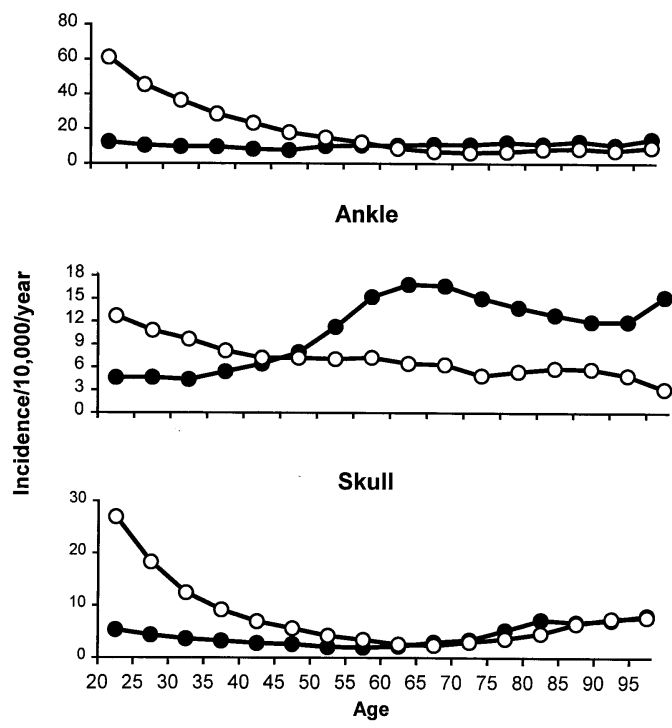
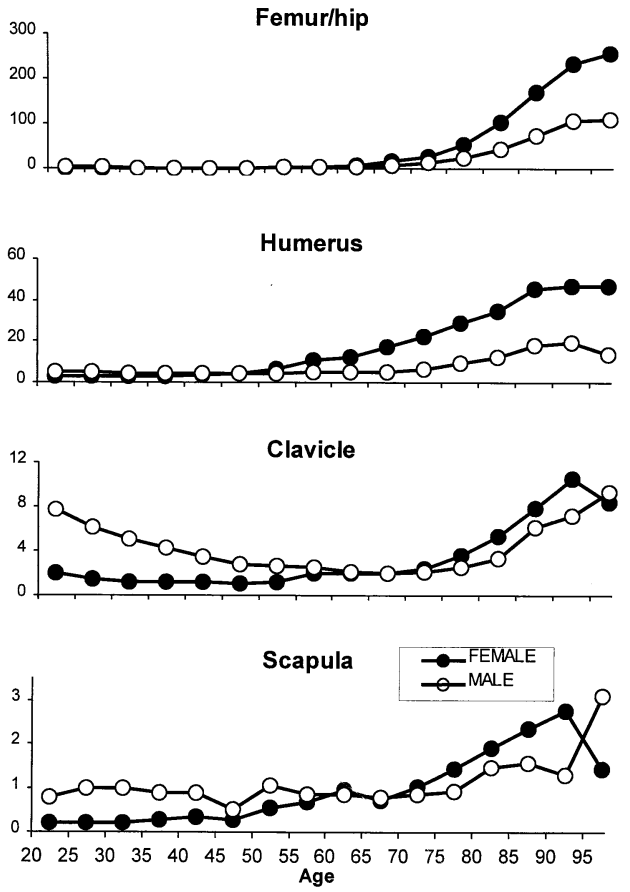

Tibia/Fibula

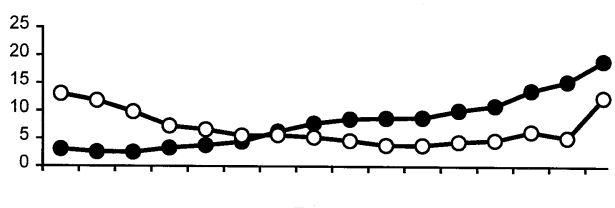

Foot
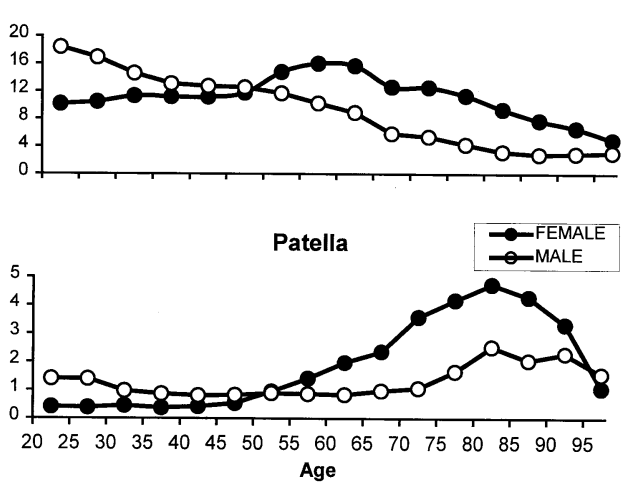

Figure 2. Age- and gender-specific incidence of fractures at selected sites among 5 million men and women registered in the General Practice Research Database, 1988-1998. (a) Fractures showing pronounced increase in incidence with age. (b) Fractures showing no apparent increase in incidence, or decrease in incidence, with advancing age. (Data available from corresponding author on request.)

rates. Fractures at all sites were slightly more common in women (107.1 per 10,000 person-years [py]) than in men (99.5 per 10,000 py). In men, the most common fracture was that of the carpal bones (26.2 per 10,000 py). There were 5755 femur/hip fractures among men (5.3 per 10,000 py). Among women, the most frequent fracture was that of the radius/ulna (30.2 per 10,000 py). There were 19,179 fractures of the femur/hip (17.0 per 10,000 py) in women. In patients aged $\geq 50$ years, the standardized incidence rate was 174.1 in women and 78.1 per
10,000 py in men. These rates were 37.2 and 11.1 , respectively, for femur/hip and 54.4 and 11.2 for radius/ulna.

Figure 1 shows the age and gender-specific incidence rates for all fractures within the cohort. Fracture incidence was greater among men than women until age 50 years, when the gender ratio reversed. At age 20 years, annual fracture incidence was 161.8 among men and 53.7 per 10,000 py among women. By age 90 years, rates were 449.3 among women and 220.9 per 10,000 py among men. 
Table 2. Estimated risks of fractures at various ages

\begin{tabular}{|c|c|c|c|c|c|}
\hline & $\begin{array}{c}\text { Current age } \\
\text { (years) }\end{array}$ & $\begin{array}{c}\text { Any } \\
\text { fractures }\end{array}$ & Radius/ulna & Femur/hip & Vertebra \\
\hline \multicolumn{6}{|l|}{ Lifetime risk } \\
\hline \multicolumn{6}{|l|}{ Women } \\
\hline & 50 & $53.2 \%$ & $16.6 \%$ & $11.4 \%$ & $3.1 \%$ \\
\hline & 60 & $45.5 \%$ & $14.0 \%$ & $11.6 \%$ & $2.9 \%$ \\
\hline & 70 & $36.9 \%$ & $10.4 \%$ & $12.1 \%$ & $2.6 \%$ \\
\hline & 80 & $28.6 \%$ & $6.9 \%$ & $12.3 \%$ & $1.9 \%$ \\
\hline \multicolumn{6}{|l|}{ Men } \\
\hline & 50 & $20.7 \%$ & $2.9 \%$ & $3.1 \%$ & $1.2 \%$ \\
\hline & 60 & $14.7 \%$ & $2.0 \%$ & $3.1 \%$ & $1.1 \%$ \\
\hline & 70 & $11.4 \%$ & $1.4 \%$ & $3.3 \%$ & $1.0 \%$ \\
\hline & 80 & $9.6 \%$ & $1.1 \%$ & $3.7 \%$ & $0.8 \%$ \\
\hline \multicolumn{6}{|l|}{10 year risk } \\
\hline \multicolumn{6}{|l|}{ Women } \\
\hline & 50 & $9.8 \%$ & $3.2 \%$ & $0.3 \%$ & $0.3 \%$ \\
\hline & 60 & $13.3 \%$ & $4.9 \%$ & $1.1 \%$ & $0.6 \%$ \\
\hline & 70 & $17.0 \%$ & $5.6 \%$ & $3.4 \%$ & $1.3 \%$ \\
\hline & 80 & $21.7 \%$ & $5.5 \%$ & $8.7 \%$ & $1.6 \%$ \\
\hline \multicolumn{6}{|l|}{ Men } \\
\hline & 50 & $7.1 \%$ & $1.1 \%$ & $0.2 \%$ & $0.2 \%$ \\
\hline & 60 & $5.7 \%$ & $0.9 \%$ & $0.4 \%$ & $0.3 \%$ \\
\hline & 70 & $6.2 \%$ & $0.9 \%$ & $1.4 \%$ & $0.5 \%$ \\
\hline & 80 & $8.0 \%$ & $0.9 \%$ & $2.9 \%$ & $0.7 \%$ \\
\hline
\end{tabular}

Figure 2 shows the incidence patterns for different fracture sites by age and gender. For some sites (Figure 2a), incidence rose steeply with advancing age (femur/hip, vertebra, humerus, pelvis, rib, clavicle, scapula, radius/ulna). For most of these sites, fracture incidence was greater among women than men, above the age of 50 years. At all of these sites, which are characterized by relatively large proportions of trabecular bone, incidence rates for fracture tended to plateau, or even decline slightly, among the oldest age categories $\left(85^{+}\right.$years). Sexual dimorphism was most apparent for fractures of the radius/ulna, where rates increased steeply with advancing age among women, but showed no such tendency among men. In the second group of fractures (Figure $2 b$ ), there was a more heterogeneous pattern of fracture incidence with advancing age. At some sites, for example, the carpus, incidence was greatest among young men, and did not increase appreciably with advancing age among men or women. At other sites, for example, the skull, patella, tibia/fibula, ankle, and foot, fracture incidence rates appeared to decline, or remain steady, with advancing age among men; rates among women at these sites showed variable patterns of age-related change.

Table 2 summarizes the estimated lifetime and 10 year risks of fracture among men and women at various ages. These estimates have been provided for any fracture site, for fractures of the radius/ulna, of the femur/hip, and of the vertebral body. At age 50 years, the remaining lifetime risk of a fracture at any site is $53.2 \%$ among women and $20.7 \%$ among men. These fall to $28.6 \%$ at age 80 years among women, and $9.6 \%$ at the same age among men. Site-specific lifetime risks at age 50 years were as follows: women, radius/ulna $16.6 \%$, femur/hip $11.4 \%$, and vertebral body $3.1 \%$; men, radius/ulna $2.9 \%$, femur/hip $3.1 \%$, and vertebral body $1.2 \%$. Table 2 also shows 10 year risks of fracture at various ages among men and women. For fractures at any site among women, the 10 year risk increased from $9.8 \%$ at age 50 years to $21.7 \%$ at age 80 years. Among men, 10 year risk remained fairly stable with advancing age $(7.1 \%$ at age 50 years and $8.0 \%$ at age 80 years). The incidence patterns of fractures at the radius/ulna, femur/hip, and vertebral body were reflected in the changing 10 year risks with advancing age. These were most stable for fractures of the radius/ulna, but rose steeply for fractures of the femur/hip and vertebral body.

Table 3 describes the observed and expected survival following fracture among men and women aged $\geq 65$ years. For fractures of the femur/hip and vertebral body, there was clear $(p<0.05)$ evidence of excess mortality up to 5 years following fracture for both genders. Fractures of the radius/ulna were only associated with slight excess mortality among men.

\section{Discussion}

This study has reported age- and gender-specific fracture incidence rates for adults in England and Wales using a large, well-validated, national cohort study. We have shown that fractures were slightly more common in women than men and that while some fractures became much more common in later life (pelvis/femur/hip) others were common in young adulthood (carpus, skull). Sexual dimorphism was apparent in fractures of the radius/ulna. In addition, whereas fractures of the femur/hip and vertebra were associated with excess mortality up to 5 years in both genders, fractures of the radius/ulna were associated with slight excess mortality in men only.

Although only $6 \%$ of the total registered population of England and Wales is represented on the database, several independent validation studies have shown that the GPRD database has a high level of completeness and validity. ${ }^{24}$ It is also broadly similar to the country as a whole in age and gender structure. Whereas ascertainment of vertebral fracture might be incomplete in this cohort, due to the low proportion of such deformities reaching clinical attention, previous studies have reported a high level of validity with respect to other fractures. ${ }^{23}$

Previous studies have attempted to describe age- and genderspecific fracture incidence rates in Britain, usually by means of fracture clinic registration systems in well-defined communities (as shown in Table 4). In one such study based in Leicestershire, ${ }^{11}$ the annual incidence of all fractures was 100 per 10,000 py for men and 81 per 10,000 py for women. Fracture incidence

Table 3. Observed and expected survival following a fracture among men and women aged $\geq 65$ years

\begin{tabular}{|c|c|c|c|c|c|c|}
\hline & \multicolumn{2}{|c|}{ Radius/ulna } & \multicolumn{2}{|c|}{ Femur/hip } & \multicolumn{2}{|c|}{ Vertebra } \\
\hline & Observed & Expected & Observed & Expected & Observed & Expected \\
\hline \multicolumn{7}{|l|}{ Women } \\
\hline At 3 months & $98.2 \%$ & $98.6 \%$ & $85.6 \%$ & $97.7 \%$ & $94.3 \%$ & $98.4 \%$ \\
\hline At 12 months & $94.0 \%$ & $94.4 \%$ & $74.9 \%$ & $91.1 \%$ & $86.5 \%$ & $93.6 \%$ \\
\hline At 5 years & $75.5 \%$ & $73.8 \%$ & $41.7 \%$ & $60.9 \%$ & $56.5 \%$ & $69.6 \%$ \\
\hline \multicolumn{7}{|l|}{ Men } \\
\hline At 3 months & $97.3 \%$ & $98.0 \%$ & $77.7 \%$ & $97.3 \%$ & $87.8 \%$ & $97.9 \%$ \\
\hline At 12 months & $89.6 \%$ & $92.4 \%$ & $63.3 \%$ & $90.0 \%$ & $74.3 \%$ & $91.8 \%$ \\
\hline At 5 years & $62.8 \%$ & $66.4 \%$ & $32.2 \%$ & $58.2 \%$ & $42.1 \%$ & $64.4 \%$ \\
\hline
\end{tabular}


was higher in men $<55$ years, but in women thereafter. In another study based in Edinburgh, ${ }^{22}$ the same peaks in fracture incidence were observed: the first in young adult men, the second in elderly patients of both genders, and the third in women $>40$ years of age (particularly of the wrist). In a Cardiff-based cohort, ${ }^{14}$ the overall incidence of fractures in this population was 211 per 10,000 py. Finally, the classic Oxford-Dundee study reported incidence rates of fractures of about 100 per 10,000 py for men and 90 per 10,000 py for women. ${ }^{4,15}$

Our own all-site fracture incidence rates are closer to those observed in Leicestershire than in Cardiff. It is possible that the Cardiff study included nonresident cases within their sample, or that fracture incidence rates are greater in South Wales compared with the country as a whole. The second of these explanations is supported by a previous study of geographic variation in hip fracture incidence rates. ${ }^{6}$ Alternatively, case ascertainment in our study may have been less complete, although fracture diagnosis has been carefully validated in the GPRD. ${ }^{23}$

The lifetime risks for hip or spine fracture in this cohort were lower than comparable figures derived from USA populations. ${ }^{17}$ There are three possible explanations for these findings: first, that the incidence rate for hip and spine fracture is indeed lower in the UK compared with the USA; ${ }^{1,9,16}$ second, that our ascertainment of hip and spine fractures was inadequate; and third, that our calculation of lifetime risk was an underestimate. It has been shown that estimates of lifetime risk of osteoporotic fracture are significantly affected by assumptions about mortality rates in the country of study, ${ }^{18}$ and our use of 1992 mortality data may have contributed to a lower-than-expected lifetime fracture risk. Using 1998 USA mortality data, the lifetime risk for a femur/hip fracture was $12.4 \%$ for a 50 -year-old woman and $3.8 \%$ for a 50-year-old man.

Numerous previous studies have suggested that fracture incidence in the community is bimodal, with peaks in youth and in the very elderly. ${ }^{6}$ In young people, fractures of the long bones predominate, usually after substantial trauma (e.g., road traffic accidents), and occur more frequently in men than women. However, at $>35$ years of age, overall fracture incidence in women climbs steeply as bone density falls, with many fractures (e.g., the hip and distal forearm) occurring twice as commonly in women as in men. Sexual dimorphism is particularly apparent in the incidence of distal forearm fracture; whereas recent studies ${ }^{20}$ have suggested that the age-adjusted incidence of forearm fractures in women increases progressively after the perimenopausal period, incidence rates in men are much lower and more constant until later life ( $>75$ years). The relation of many fractures to significant trauma in our study is reflected in high incidence rates at young ages in men (skull, carpus, foot, tibia). We found that the incidence rates of many fractures appeared to stabilize, or even fall, in extreme old age; this may reflect the influence of one or more risk factors for osteoporosis or falls, a survival advantage in the extreme elderly, or a cohort effect.

Several studies have demonstrated excess mortality in association with hip or vertebral fracture..$^{3,5,7,10,12,13}$ Hip fractures are associated with an overall reduction in survival of $10 \%-20 \%$, with the majority of deaths occurring within the first 6 months of the fracture; they may be attributed to acute fracture complications or to surgical management. In Dubbo, Australia, agestandardized mortality ratios were 2.18 for proximal femur in women and 3.17 in men, ${ }^{5}$ whereas, in the Study of Osteoporotic Fractures, ${ }^{3}$ women with fractures of the hip or pelvis had a 2.4-fold increase in mortality. One Canadian study ${ }^{10}$ attempted to evaluate factors associated with poor outcome, and reported that cognitive impairment, older age, and male gender were all adverse prognostic indicators. Our data confirm a similar excess mortality $(20 \%)$ in patients with clinically diagnosed vertebral 
fracture; this association has been reported in several previous studies, including the Rochester Epidemiology Project, ${ }^{7}$ the European Prospective Osteoporosis Study, ${ }^{13}$ and the vertebral fracture arm of the Fracture Intervention Trial. ${ }^{12}$ There appears to be a progressive divergence in observed and expected mortality rates with time, which is thought to reflect comorbidity rather than complications of the fracture, per se. By contrast, no excess mortality is observed with distal forearm fracture, perhaps reflecting a fitter, more active, underlying population. Our findings are similar to those of the Rochester Epidemiology Project ${ }^{7}$ and the Study of Osteoporotic Fractures. ${ }^{3}$ Both studies reported that there were no differences in observed and expected survival after the wrist fracture.

Incidence rates of fracture in this study were based on the occurrence of a first fracture at any site during follow-up. Repeat fracture at the same or opposite skeletal site was not included in the calculation of rates. The reason for this was that the medical records of GPRD might have contained replicate information about the same event; however, this approach may have resulted in an underestimate of the true incidence rate. Another limitation of this study concerns the limited information on the precise location of a fracture. This was due to the use of nonspecific fracture codes such as "femur fracture" for some patients. Review of the free-text information in the medical records indicates that $>90 \%$ of fractures recorded as femur fractures were proximal femur fractures. Finally, the etiology of the fracture was not always recorded, so fractures could not be classified according to the level of associated trauma. Our study only included subjects aged $\geq 20$ years; the epidemiology of fractures in childhood warrants further study.

In conclusion, we have reported age- and gender-specific incidence rates for all clinically diagnosed fractures from a representative sample of General Practices in England and Wales. We have shown a marked increase in the incidence of fractures at many sites with age, and related these clinical events to increased mortality. The data provide estimates of the public health impact of fractures that will assist in planning health services, and estimating national fracture costs.

Acknowledgments: Funds for this study were provided by a grant from Procter \& Gamble Pharmaceuticals. The authors thank EPIC, the GPRD license holder, for their support. E. Dennison and C. Cooper were supported by the Medical Research Council of Great Britain. The manuscript was prepared by G. Strange.

\section{References}

1. Baron, J. A., Karagas, M., Barrett, J., Kniffin, W., Malenka, D., Mayor, M., and Keller, R. B. Basic epidemiology of fractures of the upper and lower limb among Americans over 65 years of age. Epidemiology 7:612-618; 1996.

2. Barrett, J. A., Baron, J. A., Karagas, M. R., and Beach, M. L. Fracture risk in the US Medicare population. J Clin Epidemiol 52:243-249; 1999.

3. Browner, W. S., Pressman, A. R., Nevitt, M. C., and Cummings, S. R.
Mortality following fractures in older women. Arch Intern Med 156:1521$1525 ; 1996$.

4. Buhr, A. J. and Cooke, A. M. Fracture patterns. Lancet i:531-536; 1959.

5. Center, J. R., Nguyen, T. V., Schneider, D., Sambrook, P. N., and Eisman, J. A. Mortality after all major types of osteoporotic fracture in men and women: An observational study. Lancet 353:878-882; 1999.

6. Cooper, C. Epidemiology and public health impact of osteoporosis. Baillière's Clin Rheumatol 7:459-477; 1993.

7. Cooper, C., Atkinson, E. J., and Jacobsen, S. J., et al. Population-based study of survival after osteoporotic fractures. Am J Epidemiol 137:1001-1007; 1993.

8. Cooper, C., Campion, G., and Melton, L. J. Hip fracture in the elderly: A worldwide projection. Osteopor Int 2:285-289; 1992.

9. Cooper, C. and Melton, L. J. Epidemiology of osteoporosis. Trends Endocrinol Metab 3:224-229; 1992.

10. Cree, M., Soskolne, C. L., Belseck, E., et al. Mortality and institutionalization following hip fracture. J Am Geriatr Soc 48:283-288; 2000.

11. Donaldson, L. J., Cook, A., and Thomson, R. G. Incidence of fractures in a geographically defined population. J Epidemiol Comm Health 44:241-245; 1990.

12. Ensrud, K. E., Thompson, D. E., Cauley, J. A., et al. Prevalent vertebral deformities predict mortality and hospitalization in older women with low bone mass. J Am Geriatr Soc 48:241-249; 2000.

13. Ismail, A. A., O'Neill, T. W., Cooper, C., et al. Mortality associated with vertebral deformity in men and women: Results from the European Prospective Osteoporosis Study (EPOS). Osteopor Int 8:291-297; 1998.

14. Johansen, A., Evans, R. J., Stone, M. D., Richmond, P. W., Lo, S. V., and Woodhouse, K. W. Fracture incidence in England and Wales: A study based on the population of Cardiff. Injury 28:655-660; 1997.

15. Knowelden, J., Buhr, A. J., and Dunbar, O. Incidence of fractures in persons over 35 years of age. A report to the M.R.C. working party on fractures in the elderly. Br J Prev Soc Med 18:130-141; 1964.

16. Melton, L. J., Chrischilles, E. A., Cooper, C., Lane, A. W., and Riggs, B. L. How many women have osteoporosis? J Bone Miner Res 7:1005-1010; 1992.

17. National Osteoporosis Foundation. Osteoporosis: Review of the evidence for prevention, diagnosis, and treatment and cost-effectiveness analysis. Status Report from the National Osteoporosis Foundation. Osteopor Int 8(Suppl. 4): $10 ; 1998$

18. Oden, A., Dawson, A., Dere, W., Johnell, O., and Jonsson, B. Lifetime risk of hip fractures is underestimated. Osteopor Int 8:599-603; 1998.

19. Office for Population Censuses and Surveys. Mortality statistics: Review of the registrar general on deaths by cause, sex, and age in England and Wales, 1992. London: HMSO; 1993

20. O'Neill, T. W., Cooper, C., Finn, J. D., et al. Incidence of distal forearm fracture in British men and women. Osteopor Int 12:555-558; 2001.

21. Schouten, L. J., Straatman, H., Kiemeney, A. L. M., and Verbeek, L. M. Cancer incidence: Life table versus cumulative risk. J Epidemiol Commun Health 48:596-600; 1994.

22. Singer, B. R., McLauchlan, G. J., Robinson, C. M., and Christie, J. Epidemiology of fractures in 15,000 adults. J Bone Jt Surg 80:243-248; 1998.

23. van Staa, T. P., Abenhaim, L., Cooper, C., Begaud, B., Zhang, B., and Leufkens, H. G. M. The use of a large pharmaco-epidemiological database to study exposure to oral corticosteroids and risk of fractures: validation of study population and results. Pharmacoepidemiol Drug Saf 9:359-366; 2000.

24. Walley, T. and Mantgani, A. The UK general practice research database. Lancet 350:1097-1099; 1997

Date Received: March 20, 2001

Date Revised: June 12, 2001

Date Accepted: June 12, 2001 